\title{
Obituario de Michel Arrivé (1936-2017)
}

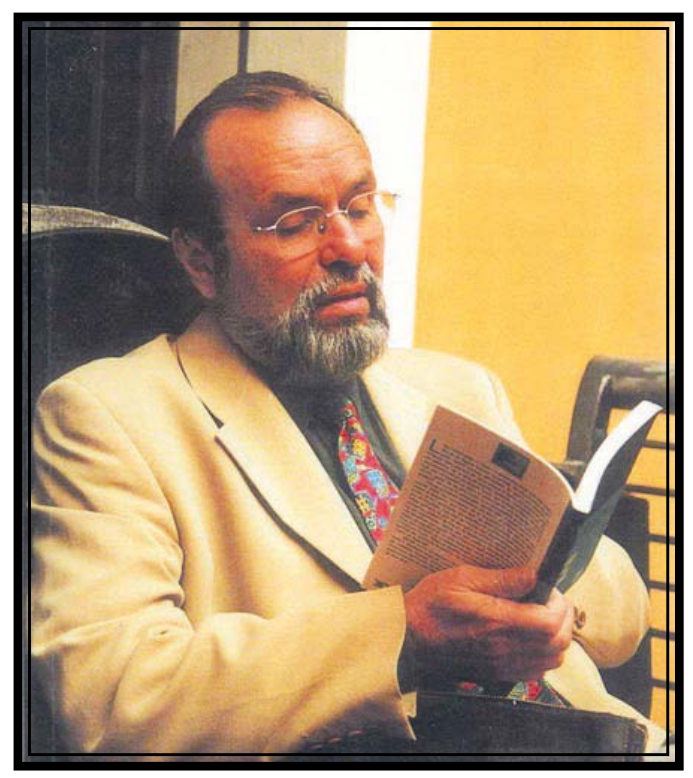

https://fr.wikipedia.org/wiki/Fichier:Michel_Arriv\%C3\%A9.jpg

El profesor lingüista Michel Arrivé falleció el 3 de abril de 2017. Se le recuerda por haber recorrido diversos campos de la lingüística y haber establecido relaciones interdisciplinares con el psicoanálisis, la teoría literaria, la semiótica y la filosofía. Fue un admirador de Alfred Jarry y un cultivador declarado de la patafísica.

Michel Arrivé, profesor emérito de la Universidad Paris X-Nanterre, se formó como gramático en la Sorbona y fue coautor de la Grammaire du français contemporain (1964) que durante mucho tiempo fue documento de consulta obligada por parte de estudiantes de todos los niveles educativos. En 1971 publica junto a Jean-Claude Chevalier un compendio teórico gramatical, La Grammaire. Lectures (Paris, Klincksieck). Más adelante, en 1986 publicó en colaboración con Françoise Gadet y Michel Galmiche, La grammaire d'aujourd'hui. Guide alphabétique de linguistique Française (Paris, Flammarion).

De igual forma, Arrivé consagró su atención a la obra de Saussure y fue organizador de coloquios y congresos dedicados al ginebrino. En el 2007 publicó un libro síntesis: A la recherche de Ferdinand de Saussure (Paris, PUF), en el 2012 presentó en la Universidad de Lyon la conferencia Un moment important dans l'histoire des sciences humaines: l'œuvre de Ferdinand de Saussure y en el 2016, en el congreso dedicado a los 100 años de publicación del CLG, el profesor Arrivé ofreció una conferencia plenaria titulada Saussure et l'inconscient.

Además de su trabajo gramatical, se interesó por la semiótica literaria y dedicó una atención particular al trabajo del creador de la patafísica Alfred Jarry en dos libros Les langages de Jarry. Essai de sémiotique littéraire (1972, Paris, Klincksieck) y Lire Jarry (1976, Paris, Presses Universitaires de France). Más aún, fue miembro activo del colegio de patafísica, divulgador del pensamiento jarriano y escritor con estilo patafísico.

$\mathrm{Su}$ ambición, con frecuencia declarada y reconocida, fue tener en cuenta el "inconsciente" y situar la obra de Freud y Lacan en el centro de 
su reflexión sobre el lenguaje y la ficción. De ahi sus libros Linguistique et psychanalyse (1986, Paris, Méridiens-Klincksieck), Langage et psychanalyse (1994, Paris, PUF) y Linguistique et inconscient, (2006, Limoges, Lambert-Lucas). Le linguiste et l'inconscient (2008, Paris, PUF).

Michel Arrivé perteneció a una generación de lingüistas que ayudaron a establecer, consolidar y desarrollar nuevos programas de lingüística en Francia durante los años 70 y 80 . Fue un divulgador del pensamiento lingüístico francés y contribuyó en gran medida, a la formación de jóvenes investigadores y futuros académicos que trabajarían en los nuevos campos de enseñanza e investigación de ciencias del lenguaje. Dirigió más de ochenta tesis, incluidas las de reconocidos académicos como Jean-René Ladmiral (traductología) Christian Puech (historia de las ideas lingüísticas), Marc Decimo (historia del arte y de las ciencias del lenguaje), Driss Ablali (semiótica textual y con quien fue coautor de un artículo muy importante: Hjelmslev et Martinet: correspondance, traduction, problèmes théoriques, La linguistique 2001/1 (Vol. 37), p. 33-58.), Dominique Maingueneau (análisis del discurso), Jean-Jacques Courtine (antropología), Daniel Delas (estilística) entre otros.

Autor de novelas y cuentos, pudo hacer uso de este tipo de adagio: el inconsciente no habla: escribe. Le gustaba definirse como «l'humble et vétilleux technicien de la lettre».

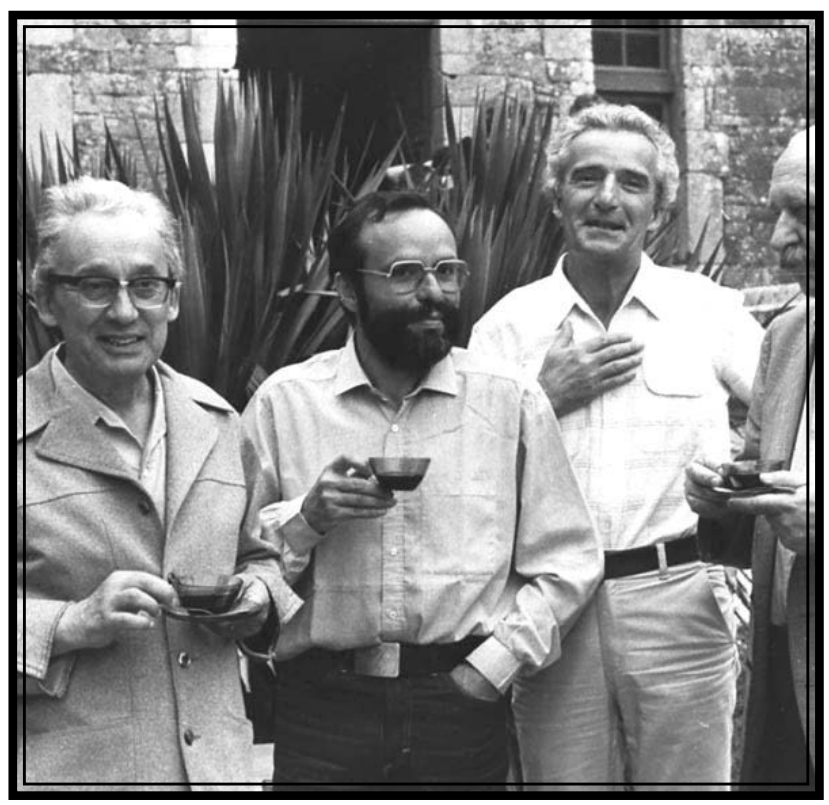

En la foto (tomada en 1983) de izquierda a derecha: Paul Ricœur, Michel Arrivé, Jean-Claude Coquet y Algirdas Julien Greimas.

http://bibliobs.nouvelobs.com/actualites/20192423.OBS8324/michel-arrive-le-linguiste-ecrivain-qui-aimait-lapataphysique.html 